\title{
Low-cost Top-down Zinc Oxide Nanowire Sensors through a Highly Transferable Ion Beam Etching for Healthcare Applications
}

\author{
K. Sun ${ }^{a}{ }^{*}$, I. Zeimpekis ${ }^{a}{ }^{*}$, C. Hu ${ }^{\text {a }}$, N. M.J. Ditshego ${ }^{a}$, O. Thomas ${ }^{b}$, M.R.R. de Planque ${ }^{\text {a }}$, H.M.H. Chong ${ }^{\text {a }}$, H. Morgan ${ }^{\text {a }}$, \\ P. Ashburn ${ }^{\text {a }}$ \\ ${ }^{a}$ Nano Research Group, University of Southampton, Southampton, SO17 1BJ, UK \\ ${ }^{\mathrm{b}}$ Oxford Instruments Plasma Technology, Yatton, Bristol, BS49 4AP, UK \\ *Email: ks5@ecs.soton.ac.uk and izk@ecs.soton.ac.uk \\ †These authors contributed equally.
}

\begin{abstract}
In this work, we demonstrate a wafer-level zinc oxide $(\mathrm{ZnO})$ nanowire fabrication process using ion beam etching and a spacer etch technique. The proposed process can accurately define nanowires without an advanced photolithography and provide a high yield over a 6-inch wafer. The fabricated nanowires are $36 \mathrm{~nm}$ wide and $86 \mathrm{~nm}$ thick and present excellent transistor characteristics. The $\mathrm{pH}$ sensitivity using a liquid gate was found to be $46.5 \mathrm{mV} / \mathrm{pH}$, while the $\mathrm{pH}$ sensitivity using a bottom gate showed a sensitivity of $366 \mathrm{mV} / \mathrm{pH}$, which is attributed to the capacitance coupling between the top- and bottom-gates. The maximum process temperature used in the fabrication of the nanowire sensors is optimized to be $200^{\circ} \mathrm{C}$ (after wet oxidation) which makes it applicable to low-cost substrates such as glass and plastic. The Ion Beam Etching (IBE) process in this work is shown to be highly transferable and can therefore be directly used to form nanowires of different materials, such as polysilicon and molybdenum disulfide, by only an adjustment of the etch time.
\end{abstract}

Keywords—ion beam etch, nanowire, zinc oxide, pH sensing, biosensor.

\section{INTRODUCTION}

Over the past decades, Ion Sensitive Field Effect Transistors (ISFETs) have been intensively researched for a wide range of sensing applications, such as ion [1], $\mathrm{pH}$ [2], DNA [3] and protein [4] sensing. Siliconbased nanowires have been of particular interest as their large surface-to-volume ratio offers a high sensitivity $[4,5]$. Nanowires fabricated in a top-down process are the preferred solution for commercialization of the technology by the semiconductor industry due to precise dimension and position control. However, when compared to conventional ISFETs, top-down silicon nanowires require costly e-beam or deep UV lithography and Silicon-on-Insulator (SOI) substrates [6,7]. To significantly reduce the fabrication cost, we have proposed a thin-film technology (TFT) alternative using polysilicon nanowires formed by reactive-ion etching (RIE) through a spacer etch technology [8]. However, the formation of polysilicon and gate dielectrics require high temperature processes such as silicon recrystallization and thermal oxidation. The high temperature budget makes this process incompatible with low-cost substrates and increases the overall cost. To overcome the temperature constraints we propose the use of zinc oxide $(\mathrm{ZnO})$ as the semiconducting layer and alumina as the gate dielectric.

$\mathrm{ZnO}$ has been a popular metal oxide semiconductor in electronics for its low cost, wide bandgap and selfdoping characteristics $[9,10]$. Recently, top-down $\mathrm{ZnO}$ nanowires were reported to be fabricated using conventional lithography, atomic layer deposition (ALD) and RIE [11]. However, the transistors of [12] were formed at chip level and cannot be directly transferred to wafer level due to issues such as chemical loading effects and plasma condition changes. The plasma-based chemical etch processes normally require complicated optimizations and are not transferable to other materials and wafer-size changes.

In this work, we report a low temperature zinc oxide nanowire sensor process that uses Ion Beam Etching (IBE) and a spacer etch technique. The proposed IBE process is highly transferable to other materials and can form $\mathrm{ZnO}$ nanowires over a 6-inch wafer with a high yield. The maximum temperature used is $200^{\circ} \mathrm{C}$ after underlying layer formation and is therefore fully compatible with low-cost substrates, which is of particular interest for point-of-care ( $\mathrm{PoC}$ ) healthcare applications. Our fabricated $\mathrm{ZnO}$ nanowire sensors show excellent transistor characteristics in air and high sensitivity to $\mathrm{pH}$ measurements. Top-gate sensing sensitivity was measured to be $46.5 \mathrm{mV} / \mathrm{pH}$ whereas bottom-gate sensing provided a sensitivity of $366 \mathrm{mV} / \mathrm{pH}$. The results are comparable with those of reported CMOS nanowire sensors [13]. 


\section{EXPERIMENTAL PROCEDURE}

The $\mathrm{ZnO}$ nanowire fabrication process is schematically shown in Figs 1a-d. The fabrication process started with a $100 \mathrm{~nm}$ silicon dioxide layer grown on a 6-inch n-type Si substrate by a wet oxidation and then a 280 $\mathrm{nm}$ silicon nitride $\left(\mathrm{Si}_{3} \mathrm{~N}_{4}\right)$ layer deposited by low pressure chemical vapor deposition (Fig. 1a). Using conventional photolithography and anisotropic RIE etching $100 \mathrm{~nm}$ deep steps were defined on the $\mathrm{Si}_{3} \mathrm{~N}_{4}$ layer (Fig. 1b). A $46 \mathrm{~nm} \mathrm{ZnO} \mathrm{layer} \mathrm{was} \mathrm{subsequently} \mathrm{deposited} \mathrm{at} 190^{\circ} \mathrm{C}$ (Fig. 1c) by an Oxford Instrument Plasma Technology (OIPT) FlexAl Atomic Layer Deposition (ALD) system using diethyl zinc (DEZ) precursor (dose time of 50 milliseconds, pressure of $80 \mathrm{mTorr})$ and oxygen plasma $\left(\mathrm{O}_{2}\right.$ flow of $60 \mathrm{sccm}$, pressure of $15 \mathrm{mTorr}$ and RF power of $100 \mathrm{~W}$ ) [12]. Subsequently, a spacer etch was done to fully remove the ZnO layer leaving $\mathrm{ZnO}$ nanowires along the $\mathrm{Si}_{3} \mathrm{~N}_{4}$ step sidewalls (Fig. 1d). The etching was done in an OIPT Ionfab 300 plus IBE system and the etching conditions were set as argon flows of $5 \mathrm{sccm}$ for the beam and $12 \mathrm{sccm}$ for the neutralizer, beam bias of $500 \mathrm{~V}$ and beam current $300 \mathrm{~mA}$, beam acceleration voltage of $400 \mathrm{~V}$, sample tilt angle of $20^{\circ}$ and chuck rotation rate of $20 \mathrm{rpm}$. The IBE was first developed on $20 \mathrm{~mm} \times 20 \mathrm{~mm}$ chips where the etch time was varied $(1.5,2$ and $2.5 \mathrm{~min})$ and the etching result was characterized by inspections with a Field Emission Scanning Electron Microscope (SEM). Unlike plasma etching processes, the ion beam etching process is a physical process based on ion bombardment and thus is not affected by the size of the area to be etched. This characteristic of IBE makes it possible to directly use a process developed at chip level to etch a full wafer. Therefore, after the optimization of the etching time using the small chips the IBE process was successfully applied to a 6-inch wafer to form the $\mathrm{ZnO}$ nanowires.

The fabricated $\mathrm{ZnO}$ nanowires can be subsequently used to form transistors/sensors capable of liquid measurements using the process described in Figs. 1e-h. During the IBE, the source and drain areas were protected by photoresist (Fig. 1e). After the etching, a $17.5 \mathrm{~nm}$ aluminum oxide $\left(\mathrm{Al}_{2} \mathrm{O}_{3}\right)$ layer was deposited on the $\mathrm{ZnO}$ as a passivation layer by a thermal $\mathrm{ALD}$ process at $200^{\circ} \mathrm{C}$ (Fig. 1f) and then partially removed by a time controlled IBE process to open metal/ $\mathrm{ZnO}$ contact windows. To etch the $\mathrm{Al}_{2} \mathrm{O}_{3}$ the same IBE process as for the $\mathrm{ZnO}$ was used by adjusting the etching time. The etch rate for $\mathrm{Al}_{2} \mathrm{O}_{3}$ was found to be $5.1 \mathrm{~nm} / \mathrm{min}$ which is expected for a hard material. The accurate and slow etch rate achieved by the IBE process allowed the full removal of $\mathrm{Al}_{2} \mathrm{O}_{3}$ over the $\mathrm{ZnO}$ layer. The ellipsometry measurements showed that the overetching of $\mathrm{Al}_{2} \mathrm{O}_{3}$ caused a $\mathrm{ZnO}$ etch of about $14 \mathrm{~nm}$ leaving enough $\mathrm{ZnO}$ to form good contacts with the metal layer. Ti/TiN contacts were then formed by sputtering and lift-off (Fig. 1g). Finally, an SU8 layer was formed using photolithography and then fully cross-linked to function as a passivation layer (Fig. 1h).

Fig. 2a shows a fabricated $\mathrm{ZnO}$ nanowire sensor including 100 parallel $40 \mu \mathrm{m}$ long nanowires with $30 \mu \mathrm{m}$ wide SU8 sensing windows. The fabricated sensors were first characterized as transistors in a dry environment and then their performance in detecting ionic changes was assessed by $\mathrm{pH}$ measurements. Fig. $2 \mathrm{~b}$ shows the configuration for $\mathrm{pH}$ sensing. We use the sensors in two different modes of operation; top-gate mode using a liquid gate formed by a $\mathrm{Ag} / \mathrm{AgCl}$ electrode, and bottom-gate mode using the backside of the substrate. For the top-gate operation, the substrate $\left(\mathrm{V}_{\mathrm{b}}\right)$ is grounded and the liquid-gate $\left(\mathrm{V}_{\mathrm{lg}}\right)$ is swept between -2 and $1 \mathrm{~V}$ with the source/drain bias set at $100 \mathrm{mV}$. For the bottom-gate operation, the liquid-gate $\left(\mathrm{V}_{\mathrm{lg}}\right)$ is grounded and the substrate $\left(\mathrm{V}_{\mathrm{b}}\right)$ is swept between -40 and $10 \mathrm{~V}$ with the same source/drain bias.

The $\mathrm{pH}$ measurements were carried out using universal buffer solutions $(0.1 \mathrm{M} \mathrm{NaCl}, 0.01 \mathrm{M}$ citric acid and $0.02 \mathrm{M}$ boric acid adjusted to $\mathrm{pH}$ values ranging from 2 to 9 by titration with a $1 \mathrm{M} \mathrm{NaOH}$ solution). The $\mathrm{pH}$ buffer solutions were consecutively applied at a decreasing $\mathrm{pH}$ order in the sensor's sensing window by pipetting. Between each buffer change, the sensors' surface were washed thoroughly with deionized wafer.

\section{RESULTS AND DISCUSSIONS}

Fig. 3 shows cross-section SEM images of an IBE nanowire (a) before etching and after (b) 1.5 minutes, (c) 2 minutes, and (d) 2.5 minutes etching. Fig. 3a shows that a $46 \mathrm{~nm} \mathrm{ZnO}$ layer covers the $100 \mathrm{~nm} \mathrm{Si}_{3} \mathrm{~N}_{4}$ step conformally. After a 1.5 minute IBE etch (Fig. 3b), the $\mathrm{ZnO}$ on the step was thinned down to $24 \mathrm{~nm}$ while the $\mathrm{ZnO}$ width near the $\mathrm{Si}_{3} \mathrm{~N}_{4}$ sidewall was barely affected. A 2 minute etching (Fig. 3c) thins down the $\mathrm{ZnO}$ 
layer such that only a very thin $10 \mathrm{~nm} \mathrm{ZnO}$ layer is left while the $\mathrm{ZnO}$ layer width next to the $\mathrm{Si}_{3} \mathrm{~N}_{4}$ sidewall is also reduced by about $10 \mathrm{~nm}$. After 2.5 minutes of etching (Fig. 3d), the $\mathrm{ZnO}$ layer is completely removed from the top and bottom planar surfaces of the step leaving only a trapezoidal shaped $\mathrm{ZnO}$ spacer next to the step. The formed spacer is effectively an $86 \mathrm{~nm}$ thick and $36 \mathrm{~nm}$ wide nanowire.

The cross-section SEM measurements (Fig. 3) were plotted as a function of $\mathrm{ZnO}$ etch time as shown in Fig. 4. It can be seen that the $\mathrm{ZnO}$ height decreases reasonably linearly with the etch time while the nanowire width remains almost the same for up to 1.5 minutes of etching at which point it starts to reduce and achieves a width of $36 \mathrm{~nm}$ in 2.5 minutes. The reduction of the width of the nanowire during etching can be attributed to the non-vertical $\mathrm{Si}_{3} \mathrm{~N}_{4}$ sidewall. The $\mathrm{Si}_{3} \mathrm{~N}_{4}$ sidewall in this work is $75^{\circ}$ which allows etching of the $\mathrm{ZnO}$ deposited on its surface. The $\mathrm{ZnO}$ IBE etch rate was found to be $18 \mathrm{~nm} / \mathrm{min}$ by fitting the $\mathrm{ZnO}$ height change with etching time. This slow etch rate can be very beneficial when etching ultra-thin layers as it can provide a fine dimension control for the formation of thin and narrow structures such as nanowires. When the etching characteristics are considered, it can be concluded that the width of the nanowire can be defined by controlling the semiconducting film thickness and angle of the $\mathrm{Si}_{3} \mathrm{~N}_{4}$ step sidewall whereas the thickness of the nanowire can be defined by controlling the $\mathrm{Si}_{3} \mathrm{~N}_{4}$ step height.

Fig. 5a shows $I_{d}-V_{d s}$ characteristics of a typical sensor with 100 nanowires in parallel, each of which is 40 $\mu \mathrm{m}$ long, measured in air with the substrate biased in the range of -10 to $10 \mathrm{~V}$. The $\mathrm{I}_{\mathrm{d}}-\mathrm{V}_{\mathrm{ds}}$ characteristics of Fig. 5a are linear, indicating that an ohmic contact is formed between $\mathrm{ZnO}$ and Ti. As it can be seen in Fig. $5 \mathrm{a}$, the drain current increases with an increasing substrate bias, which indicates that the substrate can function as a bottom-gate. Fig. $5 b$ shows an $\mathrm{I}_{d}-\mathrm{V}_{\mathrm{b}}$ characteristic of the same sensor in air using a bottom-gate sweep. The subthreshold slope (SS) extracted from the characteristic of Fig. $5 \mathrm{~b}$ is $1.41 \mathrm{~V} / \mathrm{dec}$. This is an excellent value for an equivalent bottom-gate oxide thickness of $235 \mathrm{~nm}$. To evaluate the yield of the fabrication process we measured the $\mathrm{I}_{\mathrm{d}}-\mathrm{V}_{\mathrm{ds}}$ characteristics of 54 out of the 336 transistors over the 6-inch wafer. It was found that 51 of the transistors were functional with a conductance in the expected range whereas only 3 were found nonworking. Therefore, the IBE process can be used to successfully form nanowire transistors over 6-inch wafers at a very high yield.

The results from the $\mathrm{pH}$ measurements using the top-gate are shown in Fig. 6a. $\mathrm{I}_{\mathrm{d}}-\mathrm{V}_{\mathrm{lg}}$ measurements were used to extract the sensitivity to $\mathrm{pH}$ changes. When a buffer of different $\mathrm{pH}$ is introduced in the sensing window the subthreshold $\mathrm{I}_{\mathrm{d}}-\mathrm{V}_{\mathrm{lg}}$ curve shifts because the ions of the solution change the surface potential of the sensor. As seen in Fig. 6a, the curves obtained from applying different $\mathrm{pH}$ buffers are parallel. Therefore, by selecting a reference current $\left(\mathrm{I}_{\mathrm{ref}}\right)$, the effect of $\mathrm{pH}$ change can be measured by evaluating the liquid gate voltage $\left(\mathrm{V}_{\mathrm{lg}}\right)$ shift at this reference current as shown in Fig. 6b. It can be seen that the voltage shift has a linear relation with $\mathrm{pH}$ values between 3 and 9, and the per $\mathrm{pH}$ voltage shift can be extracted from the plot to be 46.5 $\mathrm{mV} / \mathrm{pH}$. This voltage shift closely follows the literature values for an $\mathrm{Al}_{2} \mathrm{O}_{3}$ surface on nanowire sensors [13, 14]. Fig. 6c shows bottom-gate subthreshold $\left(\mathrm{I}_{\mathrm{d}}-\mathrm{V}_{\mathrm{b}}\right)$ characteristics of a typical sensor when different $\mathrm{pH}$ buffers were applied. The curves for different $\mathrm{pH}$ buffers again are approximately parallel. By defining a reference current, the voltage shift was extracted and plotted as a function of $\mathrm{pH}$ value in Fig. $6 \mathrm{~d}$. Similar to the top-gate sensing, the bottom gate shift is linear with $\mathrm{pH}$ values, with a value of $366 \mathrm{mV} / \mathrm{pH}$. Compared to the top-gate voltage shift of $46.5 \mathrm{mV} / \mathrm{pH}$, the bottom gate thus results in a significantly higher voltage shift, which is far beyond the Nerstian limit of $59 \mathrm{mV} / \mathrm{pH}$ [1]. This higher bottom-gate voltage shift has been reported previously for silicon nanowire transistors [15-17] and is explained by the effect of the capacitance coupling between the top- and bottom-gates [18]. To take advantage of the bottom-gate sensing, the proposed thin-film technology compatible fabrication process can be easily modified to integrate individual bottomgates to sensors instead of using the substrate. Therefore, the fabricated $\mathrm{ZnO}$ nanowire sensors' $\mathrm{pH}$ performance is comparable to that from other silicon based technologies but it is delivered at the temperature of $200^{\circ} \mathrm{C}$, which makes it compatible with low cost substrates such as glass and plastics.

The physical etching mechanism of IBE is known for its low selectivity over different materials, however, in a spacer etch process, it offers an excellent control over the etching and its high transferability enables the 
formation of top-down nanowires of different materials. The same IBE process, with only an etch time adjustment, can be used to form nanowires of various materials. Fig. 7 shows nanowires made from two different materials. The polysilicon nanowire in Fig. 7a was formed by a $100 \mathrm{~nm}$ Si deposition by PECVD and an IBE etch with a dimension of $85 \times 64 \mathrm{~nm}$. The spacer etch can be finely controlled as the poly-Si etch rate is only $17 \mathrm{~nm} / \mathrm{min}$. The molybdenum disulfide $\left(\mathrm{MoS}_{2}\right)$ nanowire (Fig. 7b) was also formed by a $\mathrm{MoS}_{2}$ deposition by CVD and an IBE with a dimension of $73 \times 40 \mathrm{~nm}$. The etch rate of $\mathrm{MoS}_{2}$ was found to be 14 $\mathrm{nm} / \mathrm{min}$ which is slow enough to accurately control the resulting dimensions.

\section{CONCLUSION}

In this work, we have proposed a fabrication process for zinc oxide nanowire sensors using an ion beam etching and a spacer technique to form nanowires over a 6 -inch wafer with standard $2 \mu \mathrm{m}$ minimum feature size photolithography. The results from $\mathrm{pH}$ measurements with the fabricated $\mathrm{ZnO}$ nanowire sensors showed a top-gate (liquid gate) $\mathrm{pH}$ sensitivity of $46.5 \mathrm{mV} / \mathrm{pH}$ and a bottom-gate sensitivity of $366 \mathrm{mV} / \mathrm{pH}$, which follow with those of Si nanowire sensors in the literature. The $\mathrm{ZnO}$ nanowire process is a low temperature process with a maximum temperature of $200^{\circ} \mathrm{C}$ and can be applied to low cost and disposable substrates for health care applications; this is not achievable with silicon processes because of their high temperature budgets. The $\mathrm{ZnO}$ fabrication process is compatible with thin film technologies and is therefore able to deliver sensors with individual bottom-gates, which can provide a very high voltage sensitivity. Finally, we have demonstrated that the IBE process together with the spacer etch technique is highly transferable and can be used to form top-down nanowires of other materials, including polysilicon and $\mathrm{MoS}_{2}$.

\section{ACKNOWLEDGEMENT}

The authors would like to acknowledge the Technology Strategy Board (TSB) and the Engineering and Physical Sciences Research Council (EPSRC: EP/K502327/1) for funding this work. We would also like to thank Sally Anderson, Gregory Gay, Ben Hadwen and Chris J. Brown of Sharp Laboratories Europe for many useful discussions. The data for this paper can be found at 10.5258/SOTON/383154.

\section{Reference}

[1] P. Bergveld, "Thirty years of ISFETOLOGY - What happened in the past 30 years and what may happen in the next 30 years," Sensors and Actuators B-Chemical, vol. 88, no. 1, pp. 1-20, Jan 12003.

[2] J. Bausells, J. Carrabina, A. Errachid, and A. Merlos, "Ion-sensitive field-effect transistors fabricated in a commercial CMOS technology," Sensors and Actuators B-Chemical, vol. 57, no. 1-3, pp. 56-62, Sep 71999.

[3] E. Stern, J. F. Klemic, D. A. Routenberg, P. N. Wyrembak, D. B. Turner-Evans, A. D. Hamilton, D. A. LaVan, T. M. Fahmy, and M. A. Reed, "Label-free immunodetection with CMOS-compatible semiconducting nanowires," Nature, vol. 445, no. 7127, pp. 519-522, Feb 12007.

[4] X. X. Duan, Y. Li, N. K. Rajan, D. A. Routenberg, Y. Modis, and M. A. Reed, "Quantification of the affinities and kinetics of protein interactions using silicon nanowire biosensors," Nature Nanotechnology, vol. 7, no. 6, pp. 401-407, Jun 2012.

[5] B. R. Dorvel, B. Reddy, J. Go, C. D. Guevara, E. Salm, M. A. Alam, and R. Bashir, "Silicon Nanowires with High-k Hafnium Oxide Dielectrics for Sensitive Detection of Small Nucleic Acid Oligomers," Acs Nano, vol. 6, no. 7, pp. 6150-6164, Jul 2012.

[6] Y. L. Bunimovich, Y. S. Shin, W. S. Yeo, M. Amori, G. Kwong, and J. R. Heath, "Quantitative realtime measurements of DNA hybridization with alkylated nonoxidized silicon nanowires in electrolyte solution," Journal of the American Chemical Society, vol. 128, no. 50, pp. 16323-16331, Dec 202006.

[7] J. H. Chua, R. E. Chee, A. Agarwal, S. M. Wong, and G. J. Zhang, "Label-Free Electrical Detection of Cardiac Biomarker with Complementary Metal-Oxide Semiconductor-Compatible Silicon Nanowire Sensor Arrays," Analytical Chemistry, vol. 81, no. 15, pp. 6266-6271, Aug 12009.

[8] M. M. Hakim, M. Lombardini, K. Sun, F. Giustiniano, P. L. Roach, D. E. Davies, P. H. Howarth, M. R. de Planque, H. Morgan, and P. Ashburn, "Thin Film Polycrystalline Silicon Nanowire Biosensors," Nano Lett, Mar 262012. 
[9] U. Ozgur, Y. I. Alivov, C. Liu, A. Teke, M. A. Reshchikov, S. Dogan, V. Avrutin, S. J. Cho, and H. Morkoc, "A comprehensive review of $\mathrm{ZnO}$ materials and devices," Journal of Applied Physics, vol. 98, no. 4, Aug 152005.

[10] S. J. Pearton, D. P. Norton, and F. Ren, "The promise and perils of wide-bandgap semiconductor nanowires for sensing, electronic, and photonic applications," Small, vol. 3, no. 7, pp. 1144-1150, Jul 2007.

[11] S. M. Sultan, K. Sun, O. D. Clark, T. B. Masaud, Q. Fang, R. Gunn, J. Partridge, M. W. Allen, P. Ashburn, and H. M. H. Chong, "Electrical Characteristics of Top-Down ZnO Nanowire Transistors Using Remote Plasma ALD," Ieee Electron Device Letters, vol. 33, no. 2, pp. 203-205, Feb 2012.

[12] S. M. Sultan, N. J. Ditshego, R. Gunn, P. Ashburn, and H. M. H. Chong, "Effect of atomic layer deposition temperature on the performance of top-down $\mathrm{ZnO}$ nanowire transistors," Nanoscale Research Letters, vol. 9, Sep 212014.

[13] O. Knopfmacher, A. Tarasov, W. Y. Fu, M. Wipf, B. Niesen, M. Calame, and C. Schonenberger, "Nernst Limit in Dual-Gated Si-Nanowire FET Sensors," Nano Letters, vol. 10, no. 6, pp. 2268-2274, Jun 2010.

[14] M. J. Schoning, M. Arzdorf, P. Mulchandani, W. Chen, and A. Mulchandani, "A capacitive field-effect sensor for the direct determination of organophosphorus pesticides," Sensors and Actuators BChemical, vol. 91, no. 1-3, pp. 92-97, Jun 12003.

[15] J. Go, P. R. Nair, B. Reddy, B. Dorvel, R. Bashir, and M. A. Alam, "Beating the Nernst limit of $59 \mathrm{mV} / \mathrm{pH}$ with Double-Gated Nano-Scale Field-Effect Transistors and Its Applications to UltraSensitive DNA Biosensors," 2010 International Electron Devices Meeting - Technical Digest, 2010.

[16] A. Tarasov, M. Wipf, K. Bedner, J. Kurz, W. Fu, V. A. Guzenko, O. Knopfmacher, R. L. Stoop, M. Calame, and C. Schonenberger, "True Reference Nanosensor Realized with Silicon Nanowires," Langmuir, vol. 28, no. 25, pp. 9899-9905, Jun 262012.

[17] J. H. Ahn, J. H. Eom, and B. T. Ahn, "Microstructural evolution of polycrystalline Si films during Nisilicide-mediated lateral crystallization," Journal of the Electrochemical Society, vol. 151, no. 6, pp. H141-H144, 2004.

[18] H. J. Jang, and W. J. Cho, "Fabrication of high-performance fully depleted silicon-on-insulator based dual-gate ion-sensitive field-effect transistor beyond the Nernstian limit," Applied Physics Letters, vol. 100, no. 7, Feb 132012. 


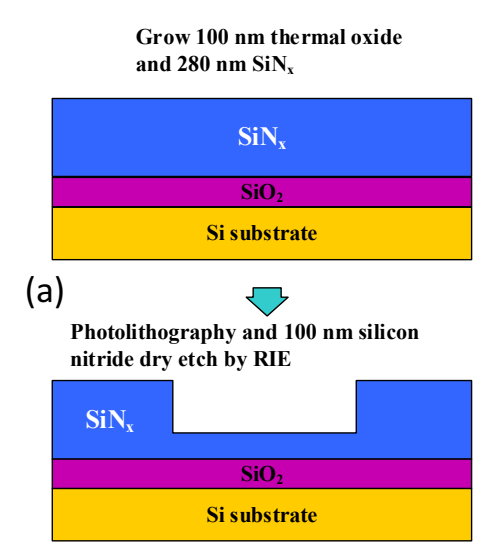

(b) Photolithography and dry etch $\mathrm{ZnO}$ to
form nanowires

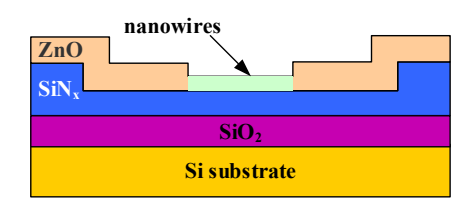

(e)

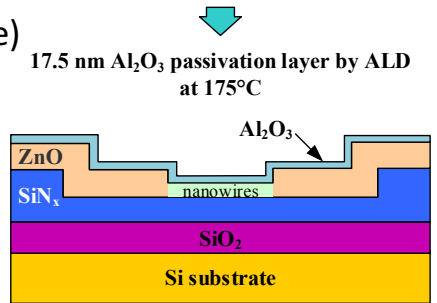

(f)
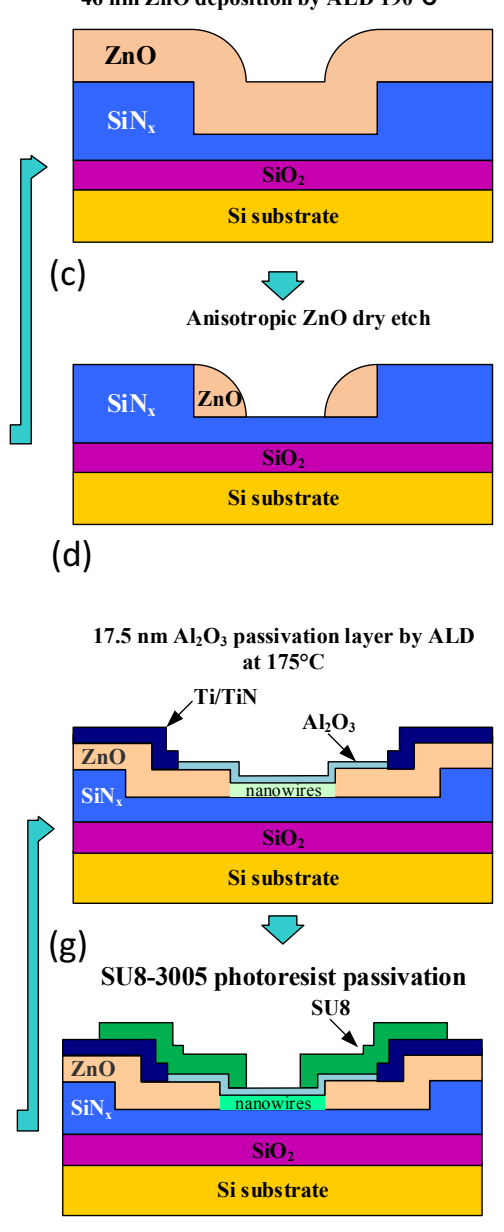

(c)

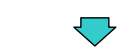

Anisotropic ZnO dry etch

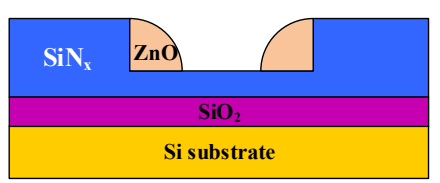

(d)

(h)
Cross-section cutline

nanowires

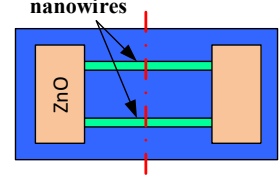

(a) to (d)

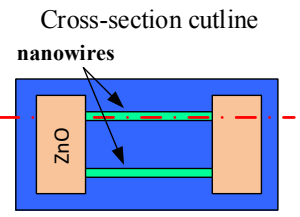

(e) to (h)

Figure 1 Schematic of the nanowire sensor fabrication process. Spacer nanowire formation (cross-section in direction perpendicular to nanowires) through dielectric formation (a), step definition by RIE silicon nitride etch (b), ZnO deposition by ALD (c) and ZnO etch by IBE (d). Sensor fabrication (cross-section in direction parallel to nanowires) through $\mathrm{ZnO}$ formation (e), $\mathrm{Al}_{2} \mathrm{O}_{3}$ passivation formation by $\mathrm{ALD}(\mathrm{f}), \mathrm{Al}_{2} \mathrm{O}_{3}$ IBE patterning and Ti/TiN electrodes by sputtering and lift-off (g), and SU8 photoresist passivation (h).

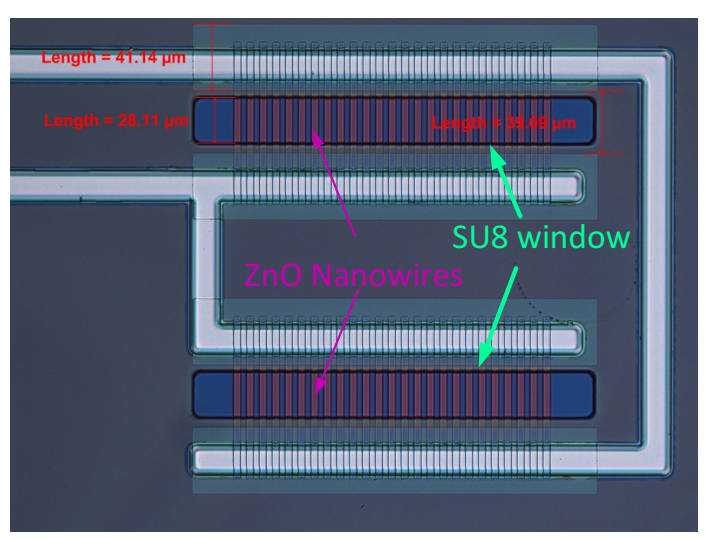

(a)

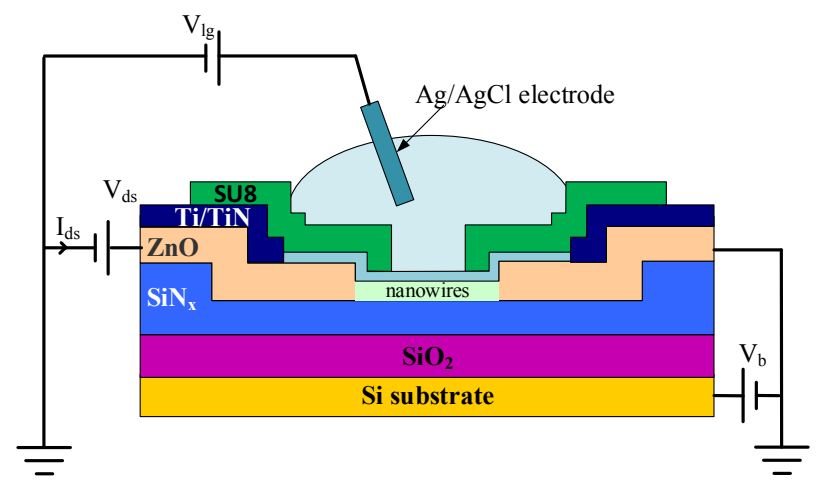

(b)

Figure 2 (a) optical micrograph of formed $\mathrm{ZnO}$ nanowire sensor and (b) $\mathrm{pH}$ measurement configuration. 


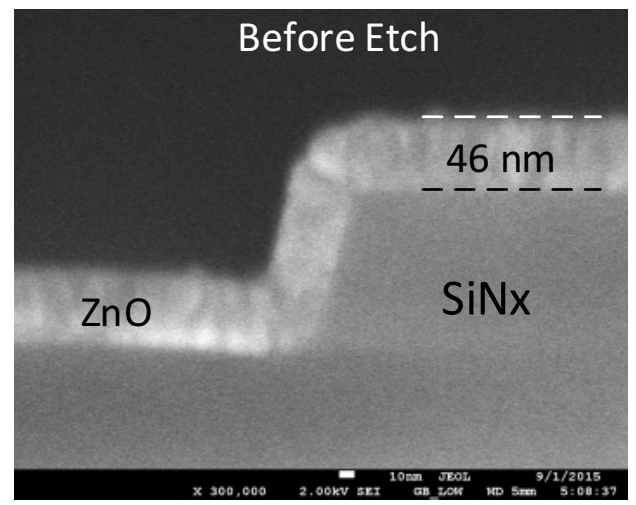

(a)

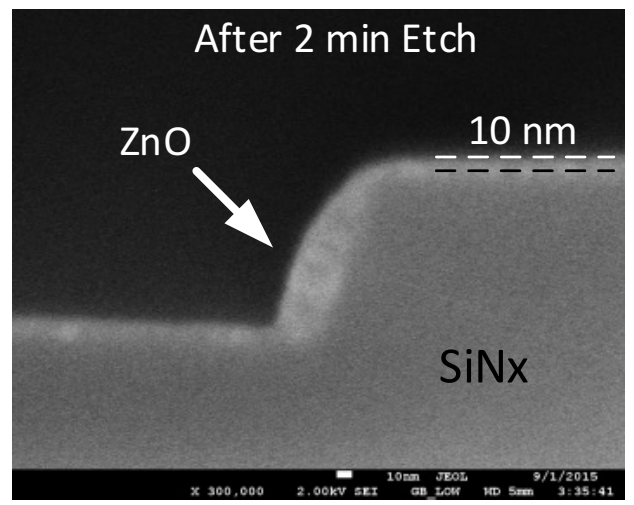

(c)

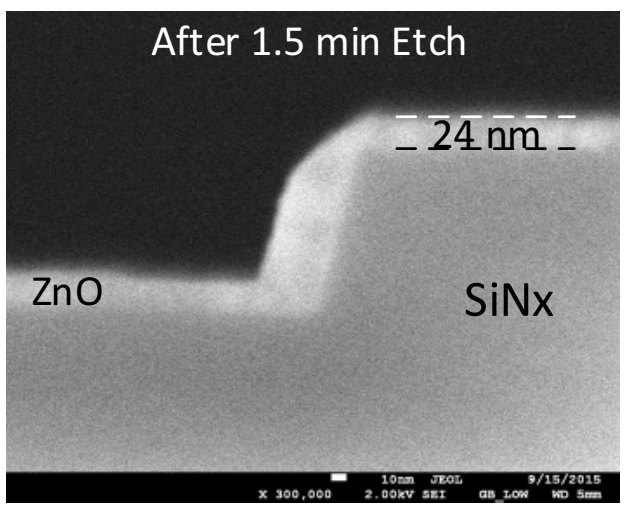

(b)

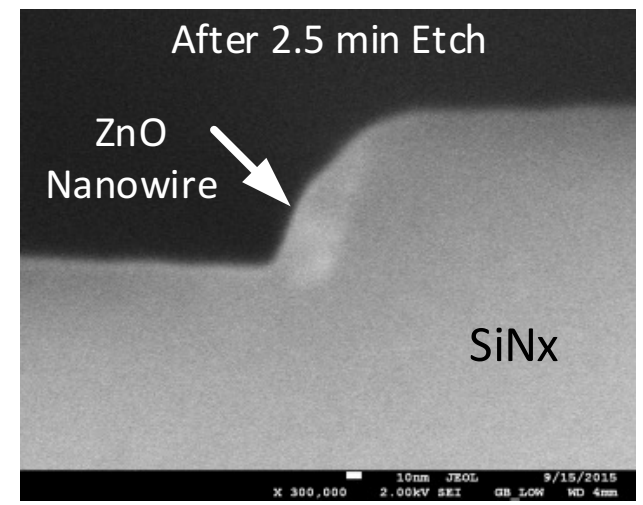

(d)

Figure 3 Cross-section SEM micrographs of $\mathrm{ZnO}$ with (a) no etch, (b) $1.5 \mathrm{~min}$ etch, (c) 2 min etch and (d) $2.5 \mathrm{~min}$ etch.

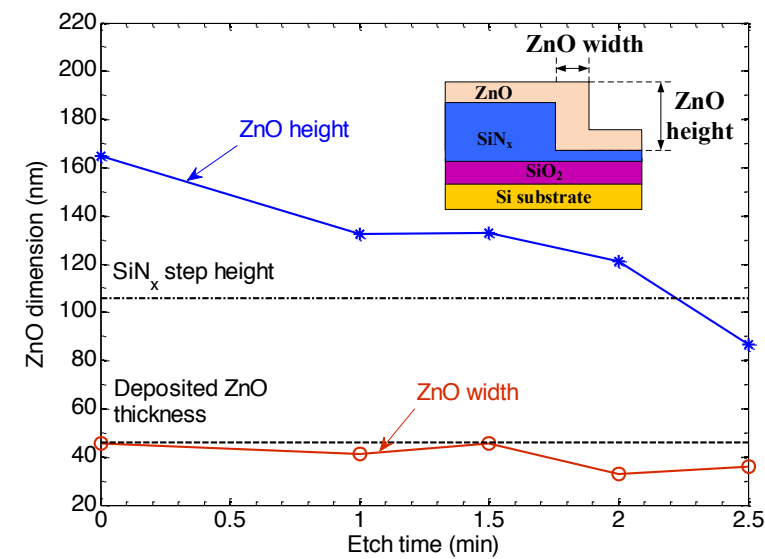

Figure 4 Nanowire width and height dimensions, measured by cross-section SEM, as a function of etch time.

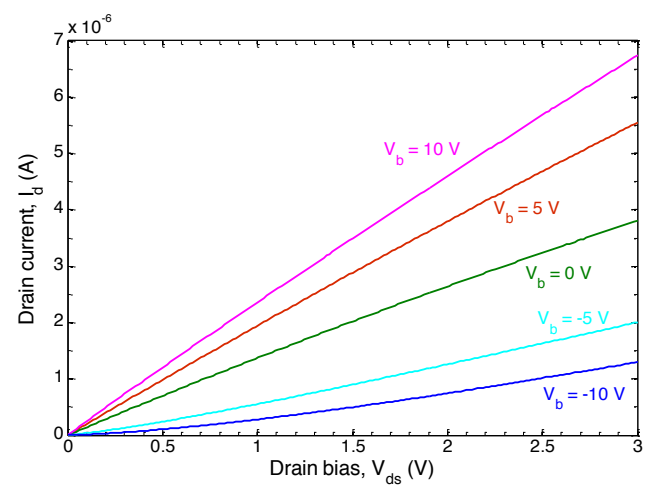

(a)

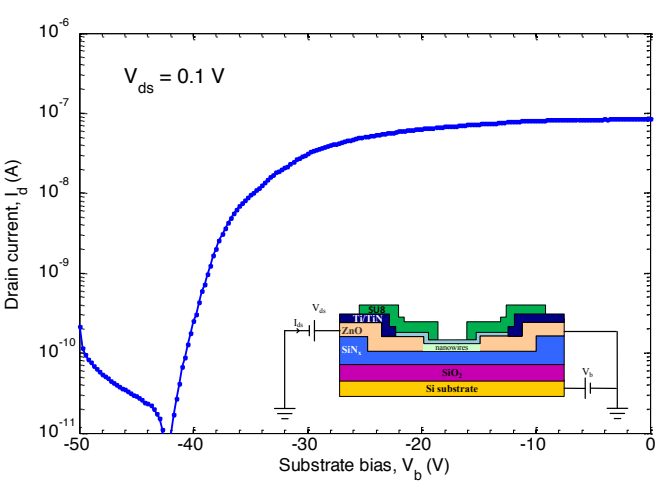

(b)

Figure 5 Nanowire sensor characterizations of (a) $I_{d}-V_{d s}$ measurements at different substrate biases, $V_{b}$, in range of -10 to $10 \mathrm{~V}$ and (b) $\mathrm{I}_{\mathrm{d}}-\mathrm{V}_{\mathrm{b}}$ subthreshold measurement at a drain bias of $0.1 \mathrm{~V}$. 


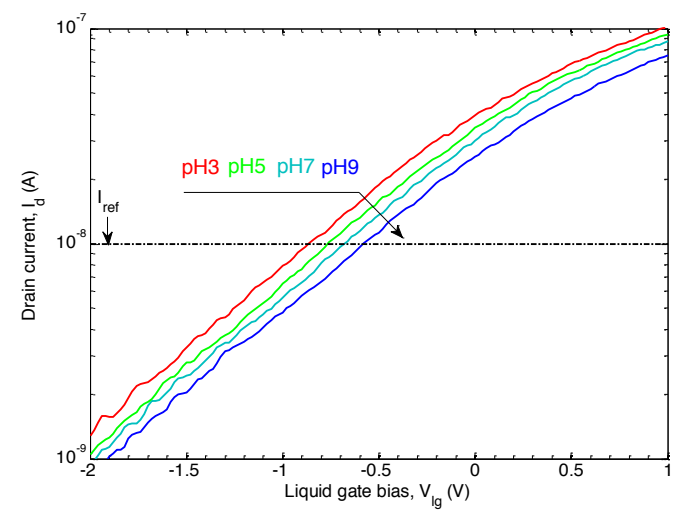

(a)

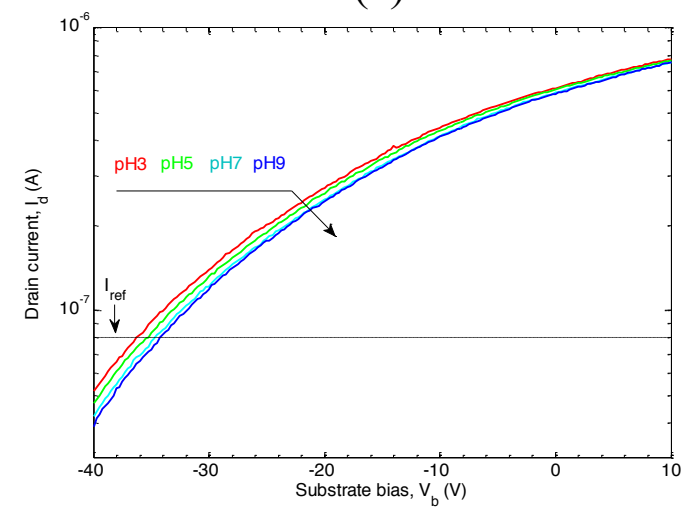

(c)

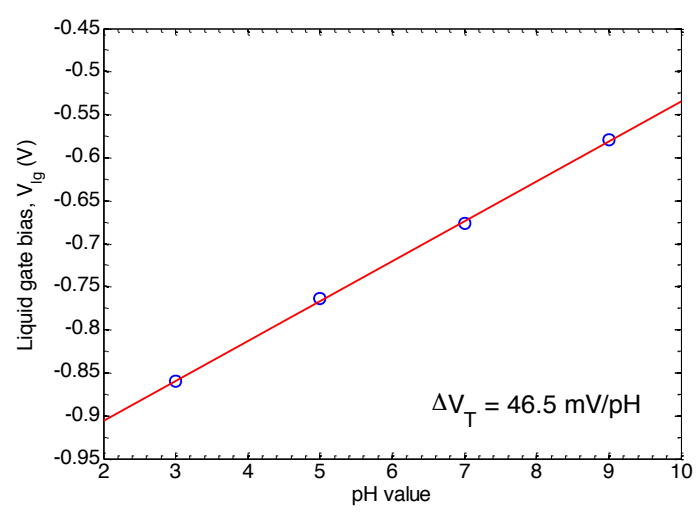

(b)

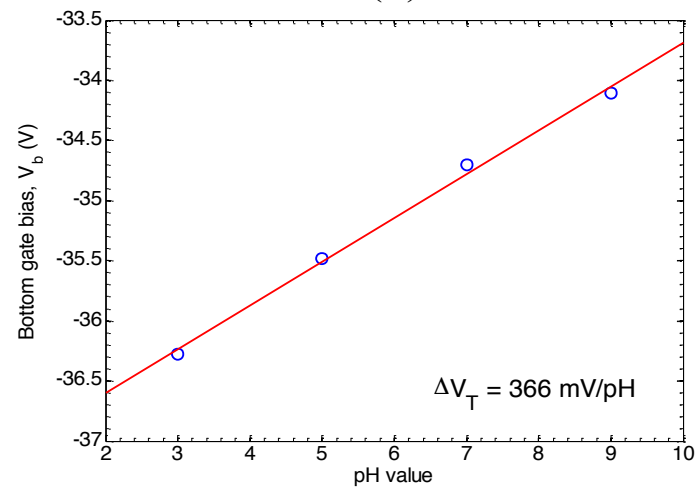

(d)

Figure $6 \mathrm{pH}$ sensing measurements using a typical $\mathrm{ZnO}$ nanowire sensor of (a) top-gate subthreshold $\left(\mathrm{I}_{\mathrm{d}}-\mathrm{V}_{\mathrm{lg}}\right) \mathrm{plots}$ at different $\mathrm{pH}$ values, (b) liquid gate bias as a function of $\mathrm{pH}$, measured at the reference current in (a), (c) bottom-gate subthreshold ( $\mathrm{I}_{\mathrm{d}}-\mathrm{V}_{\mathrm{b}}$ ) plots at different $\mathrm{pH}$ values, (b) bottom-gate bias as a function of $\mathrm{pH}$, measured at the reference current in (c).

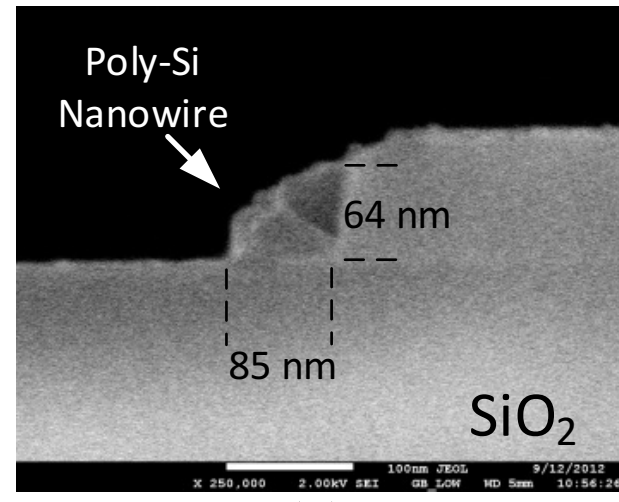

(a)

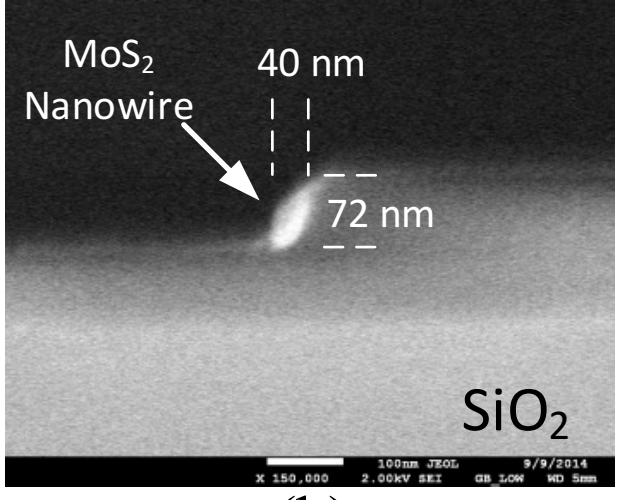

(b)

Figure 7 Cross-section SEM micrographs of nanowires formed by the same IBE process; (a) polysilicon nanowire and (b) $\mathrm{MoS}_{2}$ nanowire. 